\title{
Prevalence and correlates of sleep disorders in Greek patients with type 2 diabetes: comparison of an urban and a semi-urban population
}

Athanasia K. Papazafiropoulou ${ }^{1}$, Maria Stamatelatou², Louisa Mpoumi ${ }^{1}$, Elias Georgopoulos ${ }^{1}$, Maria Dasenaki², Andreas Melidonis ${ }^{1}$

\author{
${ }^{1}$ First Department of Internal Medicine and Diabetes Center, General Hospital \\ "Tzaneio", Piraeus, Greece \\ ${ }^{2}$ Department of Internal Medicine and Diabetes Clinic, General Hospital - \\ Health Center of Sitia, Greece
}

Submitted: 12 December 2019

Accepted: 6 January 2020

Arch Med Sci Atheroscler Dis 2020; 5: e198-e199 DOI: https://doi.org/10.5114/amsad.2020.97434 Copyright (C) 2020 Termedia \& Banach

Sleep disturbances are common in type 2 diabetes (T2D) patients [1]. To promote better management of T2D, sleep disorders must be addressed in these patients and treated early [2]. Therefore, the aim of the present study was to estimate the prevalence and correlates of sleep disorders in Greek patients with T2D, comparing an urban and a semi-urban population.

The study population comprised 308 T2D patients: 139 (80 men, mean age \pm standard deviation: $65.5 \pm 10.1$ years, glycated hemmoglobin $\left(\mathrm{HbA}_{1 \mathrm{c}}\right) 7.3 \pm 1.4 \%$, body mass index $(\mathrm{BMI}) 30.7 \pm 6.1 \mathrm{~kg} / \mathrm{m}^{2}$, duration of T2D $10.9 \pm 7.9$ years) attending the Diabetes Center of "Tzaneio" General Hospital of Piraeus (urban population, group A) and 169 (82 men, mean age: $67.9 \pm 12.4$ years, $\mathrm{HbA}_{1 \mathrm{c}} 7.0 \pm 1.3 \%$, BMI $30.8 \pm 6.1 \mathrm{~kg} / \mathrm{m}^{2}$, duration of T2D $11.2 \pm 8.7$ years) attending the Diabetes Clinic of General Hospital - Health Center of Sitia (semi-urban population, group B) from July to December 2018. Quality of sleep was evaluated by administering the Pittsburgh Sleep Quality Index (PSQI), a self-report questionnaire that assesses sleep quality and quantity over a month-long period [3].

The mean PSQI score of group A was $11.22 \pm 6.44$, while $88.5 \%$ of participants had a PSQI score $\geq 5$, indicating poor quality of sleep. The same pattern was observed in group B where the mean PSQI score was 12.48 \pm 5.85 , and $88.8 \%$ had a PSQI score $\geq 5$. Participants with a PSQI score $\geq 5$ did not differ between study groups $(p=0.13)$. Logistic regression analysis, after adjustment for sex, BMI, presence of hypertension and dyslipidemia, smoking, diabetes micro- and macrovascular complications, and oral antidiabetic treatment, showed that poor quality of sleep (PSQI score $\geq 5$ ) in the total sample population was associated with insulin treatment (odds ratio $(O R)=0.03,95 \%$ confidence interval $(95 \% \mathrm{Cl})$ : $0.31-0.99)$ and $\mathrm{HbA}_{1 c}(\mathrm{OR}=6.56,95 \% \mathrm{Cl}: 1.93-16.14)$. In group $\mathrm{A}$, poor quality of sleep was associated with insulin treatment (OR = $0.02,95 \% \mathrm{Cl}: 0.10-0.84)$ and $\mathrm{HbA}_{1 c}(\mathrm{OR}=7.55,95 \% \mathrm{Cl}: 1.97-18.81)$. In group $B$, poor quality of sleep was associated only with age $(O R=1.36$, 95\% Cl: 1.06-1.74).

Our study suggested that Greek patients with T2D have a high prevalence of sleep disorders. There was no significant difference regarding

\author{
Corresponding author: \\ Athanasia K. Papazafiropoulou \\ MD, MSc, PhD \\ First Department \\ of Internal Medicine \\ and Diabetes Center \\ General Hospital "Tzaneio" \\ 1 Zanni \& Afentouli St \\ GR-185 36, Piraeus, Greece \\ Phone: +30 6979969483 \\ E-mail: pathan@ath.forthnet.gr
}


sleep disorders between studied populations. Our analysis also indicated that insulin treatment and $\mathrm{HbA}_{1 \mathrm{c}}$ were the greatest predictors of sleep disorders. It is well known that sleep disturbances among T2D patients are associated with increased $\mathrm{HbA}_{1 \mathrm{c}}$ levels [4]. On the other hand, continuous positive airway pressure therapy of obstructive sleep apnea in T2D patients improves glycemic control [5]. In accordance with our findings, recent studies in T2D patients correlated poor sleep quality with insulin treatment $[6,7]$. Interestingly, insulin administration has been reported to be significantly correlated with sympathetic overactivity and may increase sympathetic activity [8].

In conclusion, Greek patients with T2D have a high prevalence of sleep disorders. Therefore, it is important to emphasize the need for early identification of sleep disorders in T2D patients in order to treat them early and improve patients' quality of life.

\section{Conflict of interest}

The authors declare no conflict of interest.

\section{References}

1. Chattu VK, Chattu SK, Burman D, Spence DW, PandiPerumal SR. The interlinked rising epidemic of insufficient sleep and diabetes mellitus. Healthcare 2019; 7 : pii: E37.

2. Tan X, van Egmond L, Chapman CD, Cedernaes J, Benedict C. Aiding sleep in type 2 diabetes: therapeutic considerations. Lancet Diabetes Endocrinol 2018; 6: 60-8.

3. Mollayeva T, Thurairajah P, Burton K, Mollayeva S, Shapiro CM, Colantonio A. The Pittsburgh Sleep Quality Index as a screening tool for sleep dysfunction in clinical and non-clinical samples: a systematic review and meta-analysis. Sleep Med Rev 2016; 25: 52-73.

4. Pillai A, Warren G, Gunathilake W, Idris I. Effects of sleep apnea severity on glycemic control in patients with type 2 diabetes prior to continuous positive airway pressure treatment. Diabetes Technol Ther 2011; 13: 945-9.

5. Dawson A, Abel SL, Loving RT, et al. CPAP therapy of obstructive sleep apnea in type 2 diabetics improves glycemic control during sleep. J Clin Sleep Med 2008; 4: 538-42.

6. Song Y, Ye X, Ye L, Li B, Wang L, Hua Y. Disturbed subjective sleep in Chinese females with type 2 diabetes on insulin therapy. PLoS One 2013; 8: e54951.

7. Rajendran A, Parthsarathy S, Tamilselvan B, Seshadri KG, Shuaib M. Prevalence and correlates of disordered sleep in southeast asian indians with type 2 diabetes. Diabetes Metab J 2012; 36: 70-6.

8. Perciaccante A, Fiorentini A, Paris A, Serra P, Tubani L. Circadian rhythm of the autonomic nervous system in insulin resistant subjects with normoglycemia, impaired fasting glycemia, impaired glucose tolerance, type 2 diabetes mellitus. BMC Cardiovasc Disord 2006; 6: 19. 